\title{
Improving Traffic Infrastructure in a Developing Country: An Investigation into the Usage of Public Bus Transport in Malaysia
}

\author{
Keng Lin Soh*, Wai Peng Wong, Chu Le Chong, Yan Hwan Hiew \\ School of Management, Universiti Sains Malaysia, Penang, Malaysia
}

(Received: February 7, 2014 / Revised: April 9, 2014 / Accepted: April 11, 2014)

\begin{abstract}
Economic growth with rising household income has put more vehicles on the roads worsening traffic congestion, road accidents, and air and noise pollution. This situation is further aggravated by the potential working population who choose to drive to work instead of taking public transportation. Public bus transport (PBT) plays an important role in alleviating these problems. PBT is underutilized in Malaysia, and there is an opportunity to increase ridership without substantial investment. Therefore, this study was conducted to investigate the factors that influence the use of PBT in Malaysia. The data were collected using structured questionnaires from 400 respondents. The results of the analysis show that the twin factors consisting of perceived satisfaction of and perceived importance by users towards safety and comfort of facilities and services offered by PBT are significantly related to intention to use those services. The satisfaction of availability of season tickets, the importance of reliability of bus schedule and time table, and the importance of ticket pricing are also significant. By providing insights for both public bus operators and the government, this paper contributes to mitigate the underutilization of PBT in Malaysia and the consequences of putting more vehicles on the roads. From the theory perspective, this paper also contributes by extending the theory of reasoned-action to transportation studies.
\end{abstract}

Keywords: Public Bus Transport, Satisfaction, Importance, Intention, Malaysia

* Corresponding Author, E-mail: klsoh@usm.my

\section{INTRODUCTION}

The development of socio-economic activities in some parts of the world has urbanized the cities and created traffic woes incurring economic losses (Yan et al., 2009). That development has brought negative impact with major cities introducing transportation policies to assuage these conditions by improving traffic infrastructures to attract people to use public transport (Yan et al., 2009). The cities that fail to do so would suffer the consequences of road congestion and polluted environment.

Road congestions would increase when more vehi- cles are put on the roads unless the road network and its dispersal system are effective. However, this could encourage more vehicles on the roads and reverse any gains in lowered emisisons unless it is supplemented by a road pricing system. Simulations done with three congested lanes and later de-congested with an extra lane showed a tremendous drop in emissions as follows: $\mathrm{CO}$ less $56 \%$, NOx less $61 \%$, NMVOC less $58 \%$, and $\mathrm{CO}_{2}$ less $38 \%$. Similarly, simulated emission studies showed a two-lane roadway expanded to a four-lane road experienced a drop in emissions as follows: CO less $48 \%$, NOx less $61 \%$, NMVOC less $49 \%$, and $\mathrm{CO}_{2}$ less $26 \%$ (Knudsen and Bang, 2007). These studies show a smoo- 
Improving Traffic Infrastructure in a Developing Country

Vol 13, No 2, June 2014, pp.172-184, (c) 2014 KIIE

ther traffic flow would reduce emissions.

In order to prevent or de-congest the roads to sustain the environment, various measures have been implemented by different countries. One of them is the bus rapid transport (BRT) system. One such BRT system is the Dar Es Salaam Rapid Transit (DART). The planned implementation of DART arose from several economic factors. The population of Dar Es Salaam will increase from 2.6 million habitants in 2003 to 5.8 million in 2030 . Corollary to population growth is the growth of jobs in all economic sectors of the work population. They are expected to grow from 927,534 jobs in 2002 to 2,320,000 (in 2030). An increase in jobs has to be supplemented by easy access to workplaces. The DART was expected to safeguard a sustainable environment and stave off an increase in emissions from an expected increase in traffic volume of private cars (Mzee and Chen, 2010). Even short-term traffic management measures have produced temporary positive results to pollution and health. This happened during 2008 Summer Olympic Games in Beijing when public transport was curbed (Li et al., 2011).

The usage of public bus transport (PBT) also depends on people behavior. The working population forms the potential bulk of the PBT users. Therefore, their perceptions towards the facilities and services offered by PBT are important. Almost by default, the potential working population comprises the people who would soon be completing their studies. These new employees could ride $\mathrm{PBT}$ or drive private cars to commute to their workplaces. Though PBT is one of the convenient and most affordable modes of transportation, it is still not profitable in Malaysia probably because of underutilization of its services. Incidentally, improving public transportation is also one of the six National Key Result Areas (NKRA) of Malaysia initiated in 1998, which is a priority under the Government Transformation Program (Ariff, 2011). The importance of PBT strongly shores up the argument for the need of this research to discover what factors could influence ridership in PBT.

The objective of this paper is to discover factors in PBT services that could influence the use of PBT. Therefore, this paper addresses the satisfaction and importance of the users towards PBT in several areas, such as reliability, safety, comfort, information services, season tickets and fares (pricing). They are examined against the behavioural intention of the potential users of PBT. Therefore, the research question would be "what are the satisfaction and important factors that could influence the behaviorial intention of a potential workforce to use PBT?."

This paper contributes to the practical solution of congested roads and a polluted environment. In addition, the theoretical contributions are the identification of factors that influence the ridership of PBT and the reinforcement of the practical application of the theory of reasoned action and extension of the theory to transportation. The paper is outlined as follows. In Section 2, the first part describes three PBT measures - infrastructural improvements, people behavior, and regulations - directed to increase PBT ridership, reduce traffic congestion or ill health related to air pollution. The second part describes PBT, private vehicles in Malaysia with accidents correlated to the number of cars on the roads, the justification of the use of a theory of reasoned action followed by hypothesis development. Section 3 discusses the methodology. Section 4 discusses the results and lastly Section 5 concludes the paper.

\section{LITERATURE REVIEW ON PBT}

This section comprises the measures of PBT from past researchers, the status of PBT in Malaysian context, application of theory of reasoned action and it culminates with the development of the theoretical framework and hypotheses.

\subsection{Public Transport and Bus Rapid Transport}

PBT with its renowned BRT had received much attention from several researchers. The mission of the BRT is to combine the flexibility and low implementation cost of bus service with the comfort, efficiency, cost-effectiveness, land use influence, and versatility of light rail transit (Mzee and Chen, 2010). Though the acclaimed costs of BRT is lower than mass light rail transit, it is controversial as cost models continue to be developed to assess build, implementation, and maintenance costs (Hsu, 2005, 2009). However, since BRT has its right-ofways, it should ensure better schedule reliability than conventional stage buses. And with these right-of-ways experiencing fewer traffic congestions comes the lower emisisons (Knudsen and Bang, 2007).

Mzee and Chen (2010) and Duarte and Rojas (2012) cited the first wide-scale development of BRT in $\mathrm{Cu}-$ ritiba (Brazil) in 1974 and this encouraged other cities to develop similar systems especially in several Latin American cities from Santiago of Chile to Caracas of Venezuela. The much acclaimed success of the BRT TransMilenio project in Bogotá, and the BRTs in Curitiba, Brazil, and Quito, Ecuador also drew the attention of the world as the exemplary state of the art in BRT systems (Ardila, 2007; Wright, 2003). In Mexico City, Mexico, its BRT system not only reduces air pollution, carbon emissions but also accidents and travel time (United Nations Environment Programme, 2009) implying the effectiveness of the system. Fernandez (1993) also cited PBT companies make effort to increase operating effectiveness and ease of transfer to improve the overall transit time along its routes and network. The importance of the ease of transfer is underscored by Iseki and Taylor (2009) citing walk to bus stop or work destination is real burden to a PBT user. Yet not all countries develop the BRT nor comprehensively plan commuters ease of transfers. Some would make do with the conventional or normal PBT services deploying the express bus, rapid 
bus, and mini bus or even shuttles, such as the 'tuk-tuks' in Thailand and Dhaka or the jeepneys in the Philippines (United Nations Environment Programme, 2009).

Despite the feasibility and effectiveness of BRT, there is a general increase in usage of automobiles during the last few years and this occurs in most of the urban areas in developed and developing countries. This is attributed to the mobility and flexibility afforded by private vehicles (Mohamad and Kiggundu, 2007). Private vehicles also provide several advantages, such as the privacy, comfort, unlimited usage from door-to-door, and the ability to reach any destination (Mohamad and Kiggundu, 2007). Driving expensive car models are often associated with wealth in society (Maxton and Wormald, 1995) and therefore associated also to the desire to flaunt wealth. However, it would be naïve to put blame on the advantages of private vehicles as having caused the congestion of road arteries in urban areas. Public transport can be made more attractive in the instance of the German city of Freiburg in the 1980s. The city saw a never before large rise in the demand for local public transport. Apparently this is attributed to the introduction of low cost and transferable travel cards and the continued usefulness of the cards across regions and operators (FitzRoy and Smith, 1998).

\subsection{People Behavior towards PBT}

In addition to the above PBT infrastructures, a behavioral study on public transportation in Oman deals with the situation of an insufficient public transport service capacity to match demand which has been usurped by the use of private cars (Belwal and Belwal, 2010). Therefore, that study was conducted to assess the needs and perceptions of people towards the establishment of an effective public transportation system and to identify people characteristics, such as usage behavior, experience, sharing habits, and other behavioral aspects about public transportation (Belwal and Belwal, 2010). The study found marketing of public transport services is constrained by certain environmental issues, particularly the socio-cultural and physical environments.

\subsection{Regulations -Traffic Management}

Vehicular emissions of pollutants are detrimental to health. This is described extensively in Green (1995). Kahn (1998) concluded both poor and rich households contribute to air pollution. While poorer households own vintage vehicles emitting more pollutants, the richer households tend to own new but more cars. The 2008 Summer Olympic Games in Beijing saw a decrease in the number of people visiting health clinics for asthma treatment. The data collected support efforts to reduce air pollution and improve health via reductions in motor vehicle traffic using alternative transportation strategy (Li et al., 2011).

This paper considers specifically the perceptions of a potential working population of their perception towards the facilities and services offered by PBT. Undergraduates are the potential working population who would aggravate the already congested road arteries if they drive to work in the near future. Here is the opportunity to attract this potential working population to use the existing underutilized PBT capacity in Malaysia.

\subsection{Public Bus Transport and Private Vehicles in Malaysia}

With the gradual Malaysian economic growth comes rising household income and together with the national car assembly and manufacturing industry, these form the major driving forces escalating the high dependency of private cars and therefore dominance of such vehicles on roads (Mohamad and Kiggundu, 2007). The Malaysian economy has continued to grow as evidenced by the increase in per capita income to more than US\$9,000 annually at the end of 2011 as compared to only US\$376 in 1970 (New Straits Times, 2012). Senbil et al. (2009) provided evidence of increased auto ownership with rising household income. This is also supported by empirical results of Golob (1990) suggesting contemporaneous and dynamic income effects on auto ownership. Similarly Dargay and Gately (1999) offered historical evidence of close association between income and auto ownership. In addition, according to Ohmae (1995), countries with US $\$ 3,000$ gross national product (GNP; considered income threshold) has a strong and steady demand for consumer goods, such as relatively cheap motorcars, while a GNP of US\$5,000 would demand high quality and posh cars. Therefore, the increase in new vehicle registration that grows in tandem with economic growth (Ohmae, 1995) has caused problems, such as worsening traffic congestion, road accidents, air and noise pollution in Malaysia (Mohamad and Kiggundu, 2007; Kamba et al., 2007).

Figure 1 shows vehicle ownership growing yearly except in 1998 (a consequence of the 1997 Asian financial crisis) and 2009 (due to 2008 global financial crisis). Both crises affected the demand for private motor vehicles then. However, only the drop in the 1998 demand saw a corresponding drop in road accidents in 1998 (see Figure 2). These accidents could be attributed to factors, such as deficiencies and poor management of public transport system, and boosted the private motorized transportation in most of the cities in Malaysia (Kasipillai and Chan, 2008).

The putting of more vehicles (motorcars and motorcycles) on the roads clearly has road accidents rearing its ugly head. Figure 1 shows the increasing trend in the number of vehicles on the road to the dreadful accompaniment of an increasing number of accidents along with the number of vehicles involved in those accidents (see Figure 2). In fact, the statistical correlation coefficient between the total number of registered vehicles and the number of road accidents is $0.927(p \leq 0.01)$ 


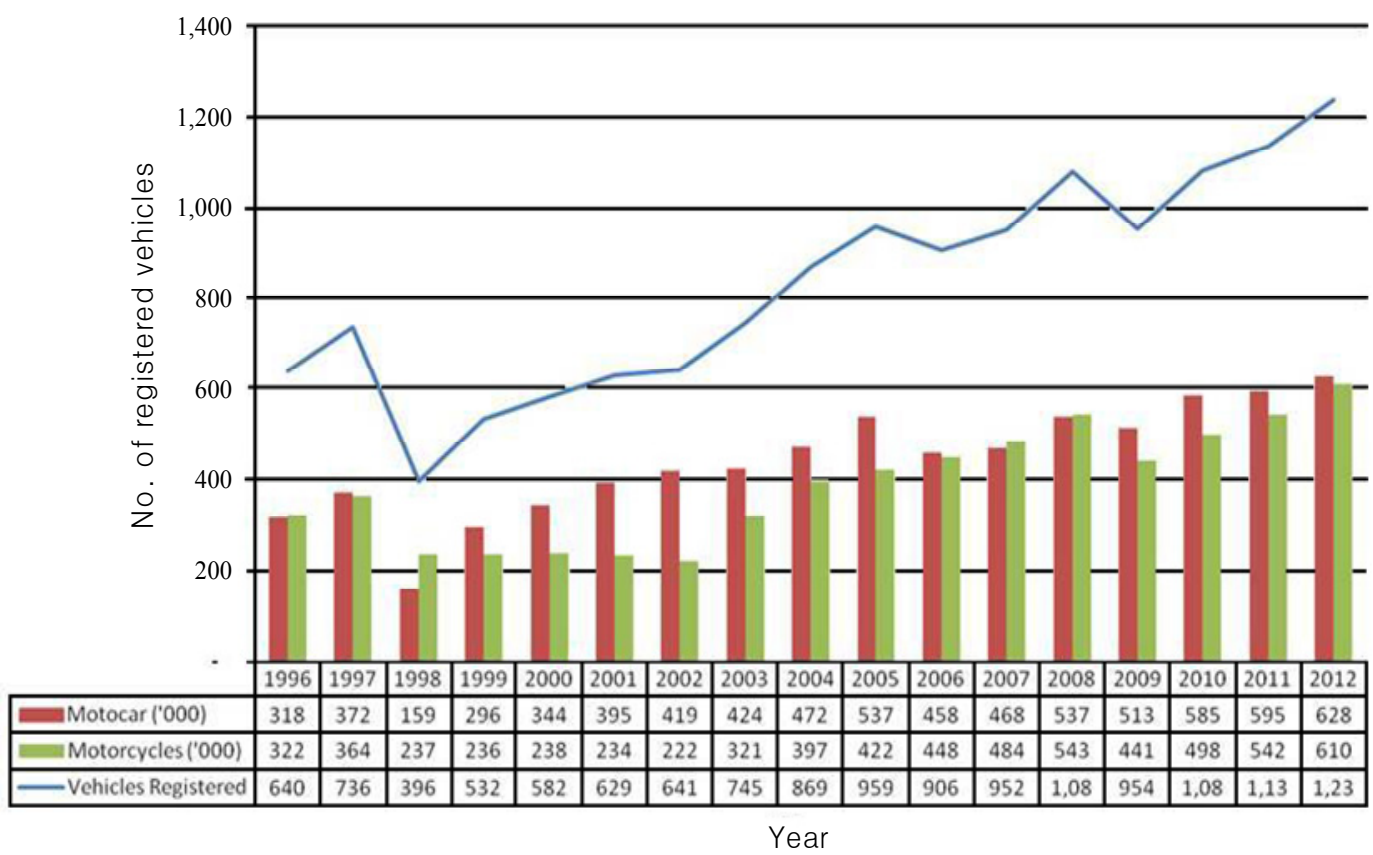

Figure 1. Malaysia: new registration of private motor vehicles (1996-2012).

General Road Accident Data (1996-2011)

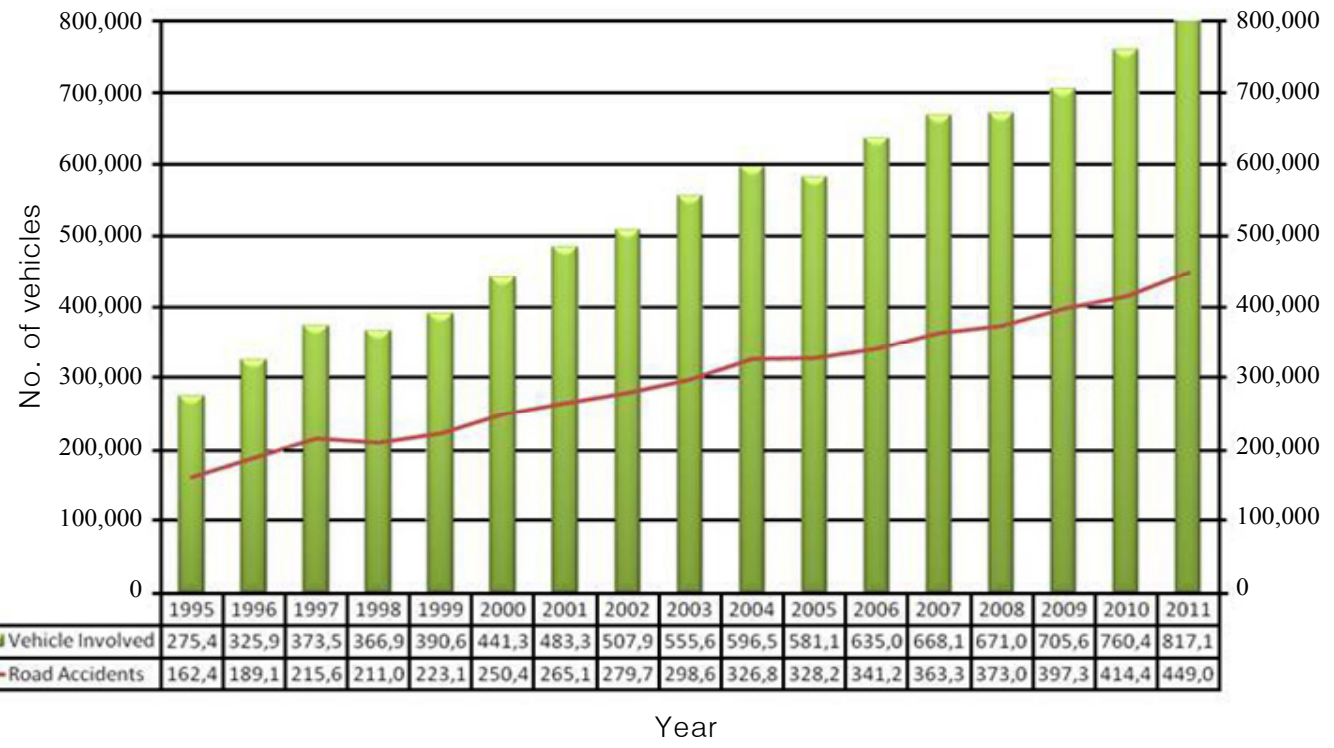

Figure 2. General road accident data (1996-2011) (Malaysian Institute of Road Safety Research, 2010).

(Table 1). Therefore, it would be obtuse to ignore the importance and usefulness to increase ridership in PBT to reduce the number of road accidents.

In Malaysia, major public transportation consists of bus, railway, and taxi services. People who choose to use public transportation enjoy several advantages one of which is the lower cost of travelling. Practically travel within the country by private cars will incur higher cost.
For example, in Kuala Lumpur which is the capital city, driving will incur the payment of toll, parking fees and obviously petrol; the local price of petrol is steadily increasing. Therefore, using public transportation should be more cost effective in the long run. While PBT fares increased $30 \%$ in 2009 , the government asserted the increase is reasonable and affordable by the lower income group (Sim, 2009). 
Table 1. Descriptive statistics

\begin{tabular}{lcccc}
\hline & Mean & SD & Total number of vehicles & Accident \\
\hline Total number of vehicles & 828176.5 & 238263 & 1 & $0.927177^{* *}$ \\
Accident & 316,991 & 85196 & $0.927177^{* *}$ & 1 \\
\hline
\end{tabular}

${ }^{* *}$ Correlation coefficient is significant at the 0.01 level (2-tailed).

\subsection{Theory of Reasoned Action}

The conceptual framework of this study is explained partly by the Theory of Reasoned Action (TRA) developed by Ajzen and Fishbein (1980). The TRA developed by Fishbein (1967) and tested by Ajzen and Fishbein (1980) is an approach to understand the individual's complex decision-making processes (Liou, 2009). TRA states individual behavior is driven by behavioral intentions which are a function of an individual's attitude towards the behavior and subjective norms surrounding the performance of the behavior. This makes attitude and subjective norms antecedent to behavioral intention. The application of TRA is widely found in information research but in the form of the Theory of Planned Behavior (TPB) which is an extension of TRA by Ajzen (1985), and the TRA is subsequently further extended to the Technology Acceptance Model (Davis, 1989).

TPB consists of an additional component called perceived behavioral control (PBC) which measures the degree of control over behavior. TPB has proven helpful in health related studies, such as quit smoking studies (Roberts, 2007). This study takes the view that such
PBC is relevant when the person would need to assess his/her own degree of ability to change. In the matter of riding in PBT, this study assumes that the degree of control over behavior would not play such a significant role as in the case of smoking addiction. Therefore, this study uses the TRA.

\subsection{Conceptual Framework and Hypotheses Development}

The two independent variables of perceived satisfaction and perceived importance in the conceptual framework of this study represent the antecedent (which is attitude) and therefore modifying the TRA. The dependent variable of intention to use public transport represents the behavioral intention of the users. Both the satisfaction level and perceived importance of facilities and services of PBT are suggested to be able to predict the individual's intention to use PBT service. Though this study does not measure actual behavior, the TRA has behavioral intention as the predictor of actual behavior (Lee and Littrell, 2005). Consequently, actual behavior would occur upon the establishment of behavioral inten-

$$
\text { Independent variables }
$$

Perceived satisfaction:

a) The reliability of bus schedule and time table

b) The safety and comfort of the bus

c) The availability of the information services

d) The availability of season ticket

e) The bus ticket pricing

Perceived importance:

a) The reliability of bus schedule and time table

b) The safety and comfort of the bus

c) The availability of the information services

d) The availability of season ticket

e) The bus ticket pricing

Behavioral intention of a potential workforce to use public bus transport service

Figure 3. Conceptual framework. 
tion to use public transport.

The independent variables of perceived satisfaction and perceived importance contain statements relating to: 1) reliability of the bus schedule and time table, 2) safety and comfort of the bus, 3) availability of information service, 4) availability of season ticket, and 5) bus ticket pricing. The dependent variable is the behavioral intention to use PBT. The following is the conceptual framework for this study (Figure 3).

The following section discusses the development of hypotheses which are generated from the various relationships of the items in the independent variables with the dependent variable.

\subsubsection{Reliability of the bus schedule and time table}

From the perspective of reliability of the bus schedule and time table, Padmanaban et al. (2009) studied the prediction of bus travel time and stated several methods are available to make public transit service more attractive, one of which is to provide accurate bus arrival time information at the bus stops. This provision will improve the perceived reliability of the public transit service. The expected bus schedule and time table will reduce the worry and the waiting time of the passengers. Bates et al. (2001) reinforced the general theory of passenger's valuation of travel time reliability. Fosgerau and Karlstrom (2010) modelled reliability into their research from that of Small (1982). They considered reliability is associated with scheduling costs as well as time and monetary costs. These researchers identified the importance of reliability in travel time. This leads to the first group of hypotheses:

H1a: The perceived satisfaction of the reliability of the bus schedule and time table is positively related to individual intention to use public transport service.

H2a: The perceived importance of the reliability of the bus schedule and time table is positively related to individual intention to use public transport service.

\subsubsection{Safety and comfort of the bus}

From the perspective of safety and comfort of the bus, several factors could contribute to vehicle accidents. These would include speeding, mechanical failures, driver fatigue, poor road and weather conditions (Af Wahlberg, 2003; Lester, 1991), and even sleep disorders (Young et al., 1997). Speed invariably has been associated with road safety that can bring about tragedies. Therefore, commuters would feel uneasy if speeding is perceived as recklessness and this could distance them from PBT services. In another study, Zarkadoula et al. (2007) stated that economical, ecological, and safe driving are aimed at reducing fuel consumption, greenhouse gas emissions, and accidents. In addition, eco-driving is concerned about driving in a way compatible with modern engine technology: smart, smooth, and safe techniques that lead to potential fuel savings of $10 \%-15 \%$. This will not only save the environment, but the smooth technique could bring comfort to the travelers. Besides, the study from Bouazara et al. (2006) showed that the seat model are related to the safety and the comfort of the bus and would increase the intention of using PBT among the users. These studies collectively support the relationship between safety and comfort towards individual intention to use public transport service. These lead to the next hypotheses:

H1b: The perceived satisfaction of the safety and comfort of the bus is positively related to individual intention to use public transport service.

$\mathrm{H} 2 \mathrm{~b}$ : The perceived importance of the safety and comfort of the bus is positively related to individual intention to use public transport service.

\subsubsection{Availability of information service}

In the research of King (1997), they identified alternative types of information that may facilitate prepurchase evaluation of services by consumers, and allow the evaluation of its usefulness and its effects on choice confidence. Consumers will consider information services, such as information about ticket price, promotional ticket, and methods to purchase the ticket, which would ease consumers' decision-making. In many service systems, commuters can also obtain information about the expected delay, and on that basis, decide whether to stay or leave (Guo and Zipkin, 2009). The information service is important for travelers to plan their journey. If the information is generally incorrect, commuters will be less likely to take PBT. That study indicated bus commuters might choose not to take PBT due to the lack of information provided. These researches clearly indicated the availability of (accurate) service information is important and is related to the intention to use of public transport. Therefore, literature supports the formulation of the following hypotheses.

H1c: The perceived satisfaction of the availability of information service is positively related to individual intention to use public transport service.

$\mathrm{H} 2 \mathrm{c}$ : The perceived importance of the availability of information service is positively related to individual intention to use public transport service.

\subsubsection{The availability of the season ticket}

Simma and Axhausen (2001) used structural equation modelling to test a priori hypotheses on the paths linking car-availability, season ticket ownership, and model usage. They found a person would prefer to own a season ticket if that person has an annual or monthly ticket for a specific area or a specific route. In addition, car owners would use less public transport. Commuters possessing season tickets would obtain the highest value for the trips made by public transport while cars commuters would obtain the lowest value for the distances travelled (Simma and Axhausen, 2001). Travel cards were intensively marketed in Swiss cities in a high- 
profile public awareness campaign with the goal to reduce environmental damage from vehicle emissions by inducing motorists to switch to public transport (FitzRoy and Smith, 1998). Therefore, the availability of season ticket is considerably related to individual's intention to use public transport service.

H1d: The perceived satisfaction of the availability of the season ticket is positively related to individual intention to use public transport service.

H2d: The perceived importance of the availability of the season ticket is positively related to individual intention to use public transport service.

\subsubsection{The bus ticket pricing}

PBT generally require commuters to pay some fare to enjoy the services. However, are the services received really worth the ticket price? The public bus transport collects fares to pay toll, petrol and for the maintenance of buses. In urban transportation systems, congestion pricing employs market forces to allocate limited road and highway capacities among travellers by their need to travel and their willingness to pay (Hamdouch et al., 2007). In a competitive market, fares should be the result of supply and demand. It should also consider the mode choices of commuters under the condition of multi-mode transportation ( $\mathrm{Si}$ and Gao, 2007).

H1e: The perceived satisfaction of the bus ticket pricing is positively related to individual intention to use public transport service.

H2e: The perceived importance of the bus ticket pricing is positively related to individual intention to use public transport service.

\section{RESEARCH METHODOLOGY}

This research is correlational and cross-sectional in nature. As mentioned earlier in Section 1, it is important to gauge the perceptions of the potential working population (i.e., the graduating students) towards the use of PBT. Our unit of analysis is the individual students from local universities in Malaysia. The rationale for choosing undergraduate students is because they would have to decide on the mode of transportation to work. In Malaysia, there are 20 public universities (Malaysia Ministry of Higher Education, http://www.mohe.gov.my/edu cationmsia/index.php? article $=$ mohe) in addition to the numerous private universities. Therefore, undergraduates form a large pool of future public transport users with an estimated 180,000 new graduates each year (Teoh, 2011). The questionnaire has a five-point Likert scale. According to Hair et al. (2010), an acceptable sample size would be ten-to-one ratio, e.g., ten respondents to one variable. In this case, the minimum sample size was determined to be 80 respondents and 400 completed questionnaires have been collected in this study and are sufficient for data analysis. Hypothesis testing using SPSS ver. 20 (IBM, Armonk, NY, USA) was used to test the relationships between the independent and dependent variables.

\subsection{Survey Questionnaire Design}

The questionnaire contains four sections. The questionnaire consists of statements and questions relating to demographics in the first section, perceived satisfaction in the second section, perceived importance in the third section, and intention to use PBT in the fourth section. The questionnaire survey is adapted from Choong (2010). Table 2 summarizes all items used and sources in Choong (2010).

\section{FINDINGS}

The age group of the 400 respondents is between 18 to 23 years of age and $75.8 \%$ of them will graduate to seek jobs soon. These respondents should be travelling to and from their work place upon their employment. The profile of respondents also shows $73 \%$ of respondents do not own vehicles. The rest would likely own motorcycles.

\subsection{Factor Analysis}

A principal component factor (PCA) analysis with a varimax rotation was conducted. In the first factor analysis, the initial solution contained five factors with eigenvalues above 1.0 for perceived satisfaction and importance, respectively. According to Kim and Mueller (1978), a factor with an eigenvalue less than 1.0 is considered less important and can be ignored. Conversely, factors comprising items with loadings greater than or equal to 0.4 were retained (Nunnally, 1967). Items with factor loadings lower than 0.4 or those loaded highly on more than two factors were eliminated (Nunnally, 1967). Therefore, five measurement items were removed. The final results of the PCA for perceived satisfaction and perceived importance on the PBT service attributes are given in Tables 3 and 4 . These results show the loadings of individual items on their corresponding factor exceeded 0.4 which confirms the items measured exhibit sufficient validity (Nunnally, 1967).

\subsection{Reliability Analysis}

The results of reliability analysis are shown in Table 3 with all Cronbach's $\alpha$ values ranging from 0.85 to 0.94 . The overall reliability coefficient scores obtained for the questionnaire is 0.91 . All coefficient $\alpha$ exceeded Nunnally (1967)'s threshold value recommended at 0.70 level of consistency confirming the items reliability and 
Table 2. Questionnaires items and sources

\begin{tabular}{|c|c|c|}
\hline Service driver & Item & Source \\
\hline \multirow{7}{*}{$\begin{array}{l}\text { Reliability } \\
\text { of schedule }\end{array}$} & 1. Bus is always punctual. & Self-experience \\
\hline & 2. More buses during peak hours. & Observation \\
\hline & $\begin{array}{l}\text { 3. Cut service to reduce number of stops with lesser commuters between two stops } \\
\text { during peak hours. }\end{array}$ & $\begin{array}{l}\text { Self-experience, } \\
\text { (Zolfaghari et al., 2004) }\end{array}$ \\
\hline & 4. Sufficient number of buses with reliable timetable during non peak hours. & Observation \\
\hline & 5. No immediate subsequent buses on the same route. & Observation, Rapid Penang \\
\hline & 6. Waiting time of $10-15$ minutes for the next bus. & Self-experience \\
\hline & 7. More buses and stops at factory, school, and residential areas. & Observation, self-experience \\
\hline
\end{tabular}

Safety and 1. Facilities and features inside the bus are in good and operational condition (e.g., (Andaleeb et al., 2007; comfort comfortable seats with enough foot space, comfortable temperature, clean floor, Shek and Chan, 2008) ceiling, bus handles and stop request buttons with comfortable height).

2. Bus is well-equipped with priority seats for the elderly, pregnant women, and dis- Observation, self-experience abled people.

3. Eco-friendly bus with less polluted solution and cleaner fuel (Green Bus).

Observation

4. Bus driver is courteous and professional.

Rapid Penang (Appendix 8.1)

5. Bus driver demonstrates appropriate and safety driving skills (does not drive too Rapid Penang, fast, overtake other vehicles dangerously, blow horn too much or frequently brake (Andaleeb et al., 2007) hard).

6. Security guidelines (against robbery, mugging, pick-pocket, bully) and safety measures (fire alarm, fire extinguisher, first aid kit, CCTV and emergency escape window) on the bus.

7. Random check by government authorities to ensure mechanical fitness and safety.

8. Covered bus stop at strategic location.

(Andaleeb et al., 2007)

(Andaleeb et al., 2007)

Feedback from pilot study

Information 1. Notice board displaying information about bus operation (bus numbers calling, Self-experience, (Molin and service timetable including departure time, arrival time and bus frequency, operating hours including the first and the last bus, midnight bus) installed at each bus stop.

2. Information about ticket price, promotional ticket and methods to get the ticket.

3. Information about network coverage area and route map.

4. Information about delay in schedule.

5. Information about seat availability and seat arrangement.

Timmermans, 2006; Neuherz et al.

2000; Vance and Balcombe, 1997)

(Molin and Timmermans, 2006;

Vance and Balcombe, 1997)

Observation, self-experience

(Molin and Timmermans, 2006;

Neuherz et al., 2000)

6. Information kiosk at the main bus station.

(Molin and Timmermans, 2006)

7. Online information and booking service.

(Molin and Timmermans, 2006)

Self-experience,

(Molin and Timmermans, 2006)

Season $\quad 1$. Weekly season ticket to travel by bus with lower rate.

Self-experience

ticket

2. Monthly season ticket to travel by bus with lower rate.

Self-experience

3. Season ticket with printed identity and photo for security purpose.

Self-experience

4. Season ticket to save time and cost of travelling.

5. Season ticket embedded in smart card for automatic ticketing.

Ticket 1. Subsidized and government supervised ticket price to travel by bus.

pricing

2. Varying ticket pricing based on availability of extra features.

Self-experience

Feedback from pilot study, self-experience

(Andaleeb et al., 2007)

3. Varying ticket pricing based on the distance travelled.

Self-experience

4. Varying ticket pricing during peak hours or peak seasons.

Self-experience

5. Varying ticket pricing for students, the elderly and disabled.

Self-experience

6 . Free ride in main city central area.

Self-experience

Observation, Self-experience 
Table 3. Results of the PCA and reliability analysis of the measurement items

\begin{tabular}{|c|c|c|c|c|c|c|}
\hline \multirow{2}{*}{ Perception } & \multicolumn{2}{|c|}{ Factor loading } & \multicolumn{2}{|c|}{ Eigenvalue } & \multicolumn{2}{|c|}{ Cronbach's $\alpha$} \\
\hline & Satisfaction & Importance & Satisfaction & Importance & Satisfaction & Importance \\
\hline Factor 1 . The reliability of bus schedule and time table & & & 4.33 & 3.88 & 0.85 & 0.87 \\
\hline Punctuality & 0.666 & 0.645 & & & & \\
\hline Availability during peak hours & 0.597 & 0.585 & & & & \\
\hline Skip bus stop to shorten cycle time & 0.668 & 0.659 & & & & \\
\hline Sufficient buses during non-peak hours & 0.721 & 0.673 & & & & \\
\hline No immediate subsequent bus on the same route & 0.654 & 0.752 & & & & \\
\hline Waiting time of $10-15$ minutes & 0.657 & 0.683 & & & & \\
\hline More buses and stop at factory, school, and residential area & - & 0.597 & & & & \\
\hline Factor 2. The safety and comfort of the bus & & & 3.88 & 6.75 & 0.85 & 0.94 \\
\hline Operational condition of facilities and features inside the bus & 0.564 & 0.673 & & & & \\
\hline Availability of priority seats & 0.718 & 0.756 & & & & \\
\hline Eco-friendly (Green bus) & 0.644 & 0.682 & & & & \\
\hline Courtesy of bus drivers & 0.620 & 0.757 & & & & \\
\hline Driving skills of bus drivers & - & 0.719 & & & & \\
\hline Security guidelines and safety measure on the bus & 0.635 & 0.726 & & & & \\
\hline Mechanical fitness and safety & 0.523 & 0.643 & & & & \\
\hline Bus stop at strategic location & - & 0.646 & & & & \\
\hline Factor 3. The availability of the information services & & & 4.76 & 4.58 & 0.91 & 0.93 \\
\hline Notice board displaying bus operation & 0.562 & 0.581 & & & & \\
\hline Method to get ticket, price, and promotional & 0.688 & 0.640 & & & & \\
\hline Network coverage area and route map & 0.699 & 0.705 & & & & \\
\hline Seat arrangement and availability & 0.649 & 0.717 & & & & \\
\hline Kiosk at the main bus station & 0.703 & 0.732 & & & & \\
\hline Online and booking service & 0.676 & 0.642 & & & & \\
\hline Delay in schedule & 0.688 & 0.540 & & & & \\
\hline Factor 4. The availability of season ticket & & & 3.73 & 4.30 & 0.93 & 0.89 \\
\hline Weekly season ticket with lower rate & 0.759 & 0.784 & & & & \\
\hline Monthly season ticket with lower rate & 0.788 & 0.769 & & & & \\
\hline Season ticket with printed identity & 0.683 & 0.610 & & & & \\
\hline Season ticket save time and cost & 0.726 & 0.677 & & & & \\
\hline Season ticket embedded in smart card for automatic ticketing & 0.621 & 0.527 & & & & \\
\hline Factor 5 . The bus ticket pricing & & & 4.18 & 2.85 & 0.89 & 0.85 \\
\hline Subsidized by government & 0.742 & 0.534 & & & & \\
\hline Varying pricing based on availability of extra features & 0.716 & 0.762 & & & & \\
\hline Varying pricing based on distance & 0.793 & 0.565 & & & & \\
\hline Varying pricing during peak hours and seasons & 0.625 & 0.764 & & & & \\
\hline Varying pricing for students, the elderly, and disabled & 0.677 & - & & & & \\
\hline Free ride in main city central area & 0.634 & - & & & & \\
\hline
\end{tabular}

PCA: principal component factor.

those above 0.80 are considered meritorious (Brah and Lim, 2006). Therefore, all questionnaire items after factor analysis are considered reliable and accepted for further analysis.

\subsection{Multiple Regression Analysis}

This analysis is carried out in order to answer the research question. The objective is to find the satisfaction and importance factors toward facilities and services of PBT as perceived by the users and how those factors relate to their intention to use PBT. From the analysis, the perceived satisfaction of the safety and comfort of the bus and the availability of season ticket are found significantly related to the individual's intention to use the PBT service. However, there is a lack of support for the relationship among the perceived satisfaction of the reliability of the bus schedule and time table, the availability of information service and ticket pricing towards the individual's intention to use PBT service. The findings of this study also failed to provide support for the existence of a relationship between the two perceived importance (availability of information service and season ticket) and the individual's intention to use the PBT service. On the other hand, the respondents consider important the reliability of bus schedule and timetable, safety and comfort of the bus and the bus ticket pricing to use PBT service.

\subsection{Discussion and Managerial Implications}

Clearly from Table 4 some managerial applications 
Table 4. Results of multiple regression analysis

\begin{tabular}{lc}
\hline \multicolumn{1}{c}{ Variable } & Standardized $\beta$ \\
\hline Perceived satisfaction & -0.009 \\
The reliability of bus schedule and time table & $0.128^{*}$ \\
The safety and comfort of the bus & $-0.179^{* *}$ \\
The availability of the information service & $0.152^{*}$ \\
The availability of season ticket & -0.073 \\
The bus ticket pricing & $0.138^{* *}$ \\
Perceived importance & $0.399^{* *}$ \\
The reliability of bus schedule and time table & 0.013 \\
The safety and comfort of the bus & 0.091 \\
The availability of the information service & $0.146^{* *}$ \\
The availability of season ticket & 0.476 \\
The bus ticket pricing & 0.462 \\
$R^{2}$ & 34.547 \\
Adjusted $R^{2}$ & 1.921 \\
$F$ value & \\
Durbin-Watson &
\end{tabular}

can be obtained from the results. The importance of safety and comfort relationship to intention to use public transport is positively correlated and of the greatest strength $(\beta=0.399)$ among all the factors, and it has a significance of $p<0.01$. Incidentally, the satisfaction of safety and comfort relationship to intention to use PBT is also significant at $p<0.05$ with $\beta=0.128$. Therefore, this particular factor of safety and comfort should be prioritized in the effort to promote intention to ride PBT as it is found occurring in both the satisfaction and importance relationships. These respondents seem to have sent the message satisfaction of the safety and comfort of bus facilities and services are important to them. Safety consciousness arises probably because of their education. The evidence has presented that bus operators should continue at least to maintain if not improve the safety and comfort aspects of PBT.

The importance of reliability of bus schedule and time table is also significant with $\beta=0.138, p<0.01$. This implies respondents see reliability as important. It could be the influence of a regimented lecture, tutorial or examination schedule that must be adhered to with punctuality.

Another factor which is significant is the satisfaction of availability of season tickets $(\beta=0.152, p<$ $0.05)$. These potential users probably enjoy discounts that come along with season tickets. Quite understandably, they would prefer season tickets which are cheaper since they are not working yet. In addition, this could also be attributed to the added convenience and efficiency of using season tickets which normally reduce transaction time.
The importance of ticket pricing is also significant with $\beta=0.146, p<0.01$. Undoubtedly, this relates to the financial ability of respondents and upon graduation. Fresh graduates at market entry level would normally command relatively low pay with most trying to make ends meet. Therefore, even nominal savings would be important to them.

However, what seems interesting is the satisfaction of availability of information service having a $\beta=-0.179$, $p<0.01$. This would mean that even if information is not available, the intention to use PBT still remains. This could explain these potential users have no better choices but to use PBT service even if it means having to suffer the uncertainty of having no information.

\section{CONCLUSIONS}

This study was initiated to find out the satisfaction and perceived importance by the potential working population towards facilities and services of PBT and their intention to ride in PBT. It also fulfills the National Key Research (NKRA) to improve public transport initiated by the Malaysian government. The findings mentioned above bring into focus those attributes for improvement by both public bus operators and the government to mitigate the underutilization of PBT transport in Malaysia and the dreaded consequences of putting more vehicles on the roads. The results showed that the potential working population who will enter the work market seem to prioritize safety and comfort for their ride. Furthermore, this group of users who normally have 
a relatively lower starting pay upon employment would prefer to have season tickets which is usually cheaper and convenient. Therefore, ticket pricing also features significantly in the satisfaction relationship to the intention to use PBT. Reliability of bus schedule and time table also features importantly in the intention to use PBT. All these taken together represent a populace who seem to know what they want. Therefore, stakeholders, such as bus operators and the government, should work towards safety, comfort, reliability to increase ridership either through infrastructural improvements or behavioral controls, such as providing incentives for using PBT.

Though this paper has provided some insights into the factors affecting the use of PBT in Malaysia, it is not without limitations. This study only focuses on the five factors of satisfaction and importance. There are numerous other socio-political-economic factors relating to intention to use bus services, such as income level, government enforcement of road pricing, domestic car manufacturing policies, affordability to maintain cars, road networks and dispersal system. Future research could include investigation into those areas.

\section{ACKNOWLEDGMENTS}

This research was funded by an incentive grant from the Universiti Sains Malaysia, Penang, Malaysia, under grant number (304/JPNP/600004). The authors are thankful to Krishnaswamy Jeyaraman Ph.D., Jacylin Shiau Suan Choong, and Keng Lin Soh for the use of their questionnaires. The authors would also like to thank all respondents who have participated in this survey.

\section{REFERENCES}

Af Wahlberg, A. E. (2003), Some methodological deficiencies in studies on traffic accident predictors, Accident Analysis and Prevention, 35(4), 473-486.

Ajzen, I. (1985), From intentions to actions: a theory of planned behavior. In: Kuhl, J. and Beckman, J. (eds.), Action Control, Springer, Heidelberg, 11-39.

Ajzen, I. and Fishbein, M. (1980), Understanding Attitudes and Predicting Social Behavior, PrenticeHall, Englewood Cliff, NJ.

Andaleeb, S. S., Haq, M., and Ahmed, R. I. (2007), Reforming innercity bus transportation in a developing country: a passenger-driven model, Journal of Public Transportation, 10(1), 1-25.

Ardila, A. (2007), How public transportation's past is haunting its future in Bogota, Colombia, Transportation Research Record: Journal of the Transportation Research Board, 2038, 9-15.

Ariff, M. M. (2011), High hopes for Malaysia's mega mass rapid transit (MRT), Available from: http:// greaterkl.bernama.com/excnews.php?id=562431.

Bates, J., Polak, J., Jones, P., and Cook, A. (2001), The valuation of reliability for personal travel, Transportation Research Part E: Logistics and Transportation Review, 37(2), 191-229.

Belwal, R. and Belwal, S. (2010), Public transportation services in Oman: a study of public perceptions, Journal of Public Transportation, 13(4), 1-21.

Bouazara, M., Richard, M. J., and Rakheja, S. (2006), Safety and comfort analysis of a 3-D vehicle model with optimal non-linear active seat suspension, $\mathrm{Jo}$ urnal of Terramechanics, 43(2), 97-118.

Brah, S. A. and Lim, H. Y. (2006), The effects of technology and TQM on the performance of logistics companies, International Journal of Physical Distribution and Logistics Management, 36(3), 192209.

Choong, J. S. S. (2010), Conceptualization of perceived utilization of public bus transport service: empirical evidence for Malaysia transport sustainability, dissertation, Universiti Sains Malaysia, Pulau Pinang.

Dargay, J. and Gately, D. (1999), Income's effect on car and vehicle ownership, worldwide: 1960-2015, Transportation Research Part A: Policy and Practice, 33(2), 101-138.

Davis, F. D. (1989), Perceived usefulness, perceived ease of use, and user acceptance of information technology, MIS Quarterly, 13(3), 319-340.

Duarte, F. and Rojas, F. (2012), Intermodal connectivity to BRT: a comparative analysis of Bogotá and $\mathrm{Cu}-$ ritiba, Journal of Public Transportation, 15(2), 118.

Fernandez, R. (1993), An expert system for the preliminary design and location of high-capacity bus-stops, Traffic Engineering and Control, 34(11), 533-539.

Fishbein, M. (1967), A behavior theory approach to the relations between beliefs about an object and the attitude toward the object. In: Readings in Attitude Theory and Measurement, John Wiley and Sons, New York, NY, 389-399.

FitzRoy, F. and Smith, I. (1998), Public transport demand in Freiburg: why did patronage double in a decade? Transport Policy, 5(3), 163-173.

Fosgerau, M. and Karlstrom, A. (2010), The value of reliability, Transportation Research Part B: Methodological, 44(1), 38-49.

Golob, T. F. (1990), The dynamics of household travel time expenditures and car ownership decisions, Transportation Research Part A: General, 24(6), 443463.

Green, M. (1995), Not a crisis, but action is needed, Available from: http://www.bmj.com/content/311/ 7002/401.

Guo, P. and Zipkin, P. (2009), The effects of the avail- 
ability of waiting-time information on a balking queue, European Journal of Operational Research, 198(1), 199-209.

Hair, J. F., Black, W. C., Babin, B. J., and Anderson, R. E. (2010), Multivariate Data Analysis (7th ed.), Prentice Hall, Upper Saddle River, NJ.

Hamdouch, Y., Florian, M., Hearn, D. W., and Lawphongpanich, S. (2007), Congestion pricing for multimodal transportation systems, Transportation Research Part B: Methodological, 41(3), 275-291.

Hsu, L. R. (2005), Capacity-based cost modeling for light rail and bus rapid transit systems, thesis, Florida International University, Miami, FL.

Hsu, L. R. (2009), Project cost models for mode choice between light rail and bus rapid transit systems, Proceedings of the Transportation Research Board 88th Annual Meeting, Washington, DC, article no. 09-0763.

Iseki, H. and Taylor, B. D. (2009), Not all transfers are created equal: towards a framework relating transfer connectivity to travel behavior, Transport Reviews, 29(6), 777-800.

Kahn, M. E. (1998), A household level environmental Kuznets curve, Economics Letters, 59(2), 269-273.

Kamba, A. N., Rahmat, R. A. O., and Ismail, A. (2007), Why do people use their cars: a case study in Malaysia, Journal of Social Sciences, 3(3), 117-122.

Kasipillai, J. and Chan, P. (2008), Travel demand management: lessons for Malaysia, Journal of Public Transportation, 11(3), 41-55.

Kim, J. O. and Mueller, C. W. (1978), Factor Analysis: Statistical Methods and Practical Issues, Sage Publications, Thousand Oaks, CA.

King, M. F. (1997), The effects of alternative information availability on consumer decision strategies for professional services: a cross-cultural perspective, Journal of Retailing and Consumer Services, 4(1), 1-11.

Knudsen, T. and Bang B. (2007), Environmental consequences of better roads, Report no. STF50 A07034, SINTEF Technology and Society, Road and Transport Studies, Trondheim, Norway.

Lee, S. E. and Littrell, M. A. (2005), Global e-tailing: US consumers' intention to shop for cultural products on the Internet, International Journal of Retail and Distribution Management, 33(2), 133-147.

Lester, J. (1991), Individual Differences in Incident Liability: Review of the Literature, Transport and Road Research Laboratory, Crowthorne, UK.

Li, Y., Wang, W., Wang, J., Zhang, X., Lin, W., and Yang, Y. (2011), Impact of air pollution control measures and weather conditions on asthma during the 2008 Summer Olympic Games in Beijing, International Journal of Biometeorology, 55(4), 547-554.

Liou, S. R. (2009), Nurses' intention to leave: critically analyse the theory of reasoned action and organizational commitment model, Journal of Nursing Management, 17(1), 92-99.

Malaysian Institute of Road Safety Research (2010), General road accident data in Malaysia (19952010), Available from: http://www.miros.gov.my/ web/guest/road.

Maxton, G. P. and Wormald, J. (1995), Driving Over a Cliff? Business Lessons from the World's Car Industry, Economist Intelligence Unit, London.

Mohamad, J. and Kiggundu, A. T. (2007), The rise of the private car in Kuala Lumpur, Malaysia: assessing the policy options, IATSS Research, 31(1), 6977.

Molin, E. J. and Timmermans, H. J. (2006), Traveler expectations and willingness-to-pay for Web-enabled public transport information services, Transportation Research Part C: Emerging Technologies, 14(2), 57-67.

Mzee, P. K. and Chen, Y. (2010), Implementation of BRT system in developing countries as the best option in reducing emission the case study of Dart system in Dar es Salaam, Proceedings of the IEEE International Conference on Advanced Management Science, Chengdu, China, 532-537.

Neuherz, M., Patz, V., Pischner, T., and Keller, H. (2000), User acceptance and impacts of new multimodal traffic information services in BAYERNINFO, Proceedings of the 7th World Congress on Intelligent Transport Systems, Turin, Italy.

New Straits Times (2012), Malaysia's per capita income rises, Available from: http:/www.nst.com.my/latest/ malaysia-s-per-capita-income-rises-1.46403.

Nunnally, J. C. (1967), Psychometric Theory, McGrawHill Education, New Delhi.

Ohmae, K. (1995), The End of the Nation State: The Rise of Regional Economies, Free Press, New York, NY.

Padmanaban, R. P. S., Vanajakshi, L., and Subramanian, S. C. (2009), Automated delay identification for bus travel time prediction towards APTS applications, Proceedings of the 2nd International Conference on Emerging Trends in Engineering and Technology, Nagpur, India, 564-569.

Roberts, C. N. (2007), Applying the theory of planned behavior to the intent to quit smoking among pregnant women, dissertation, The University of Alabama at Birmingham, Available from: http:/grad works.umi.com/32/53/3253070.html.

Senbil, M., Kitamura, R., and Mohamad, J. (2009), Residential location, vehicle ownership and travel in Asia: a comparative analysis of Kei-Han-Shin and Kuala Lumpur metropolitan areas, Transportation, 36(3), 325-350.

Shek, K. W. and Chan, W. T. (2008), Combined comfort model of thermal comfort and air quality on 
buses in Hong Kong, Science of the Total Environment, 389(2-3), 277-282.

$\mathrm{Si}$, B. and Gao, Z. (2007), Optimal model for passenger transport pricing under the condition of market competition, Journal of Transportation Systems Engineering and Information Technology, 7(1), 72-78.

Sim, L. L. (2009), Cabinet approves new bus, taxi fares, Available from: http://thestar.com.my/news/story. asp?file $=/ 2009 / 7 / 16 /$ nation $/ 20090716122039 \& \sec =$ nation.

Simma, A. and Axhausen, K. W. (2001), Structures of commitment in mode use: a comparison of Switzerland, Germany and Great Britain, Transport Policy, 8(4), 279-288.

Small, K. A. (1982), The scheduling of consumer activities: work trips, The American Economic Review, 72(3), 467-479.

Teoh, S. (2011), Malaysian graduates struggle to get good jobs, says Straits Times, Available from: $\mathrm{http}: / / \mathrm{www}$.themalaysianinsider.com/malaysia/artic le/malaysian-graduates-struggle-to-get-good-jobssays-straits-times.

United Nations Environment Programme. (2009), Sustainable Urban Energy Planning: A handbook for Cities and Towns in Developing Countries, United Nations Human Settlements Programme (UN-HABITAT), Nairobi.

Vance, C. and Balcombe, R. J. (1997), How to tell bus passengers what they need to know, In: Public
Transport Planning and Operation: Proceedings of Seminar $G$ held at the European Transport Forum Annual Meeting, Uxbridge, England, 231-242.

Ward, N. J. (2000), Automation of task processes: an example of intelligent transportation systems, $H u$ man Factors and Ergonomics in Manufacturing and Service Industries, 10(4), 395-408.

Wright, L. (2003), Bus Rapid Transit, Deutsche Gesellschaft fur Technische Zusammenarbeit (GTZ), Eschborn.

Yan, W., Li, X., and Ding, T. (2009), Urban public transportation modes coupling study based on residents travelling, Proceedings of the 5th Advanced Forum on Transportation of China, Beijing, China, 181-186.

Young, T., Blustein, J., Finn, L., and Palta, M. (1997), Sleepiness, driving and accidents: sleep-disordered breathing and motor vehicle accidents in a population-based sample of employed adults, Sleep, 20(8), 608-613.

Zarkadoula, M., Zoidis, G., and Tritopoulou, E. (2007), Training urban bus drivers to promote smart driving: a note on a Greek eco-driving pilot program, Transportation Research Part D: Transport and Environment, 12(6), 449-451.

Zolfaghari, S., Azizi, N., and Jaber, M. Y. (2004), A model for holding strategy in public transit systems with real-time information, International Journal of Transport Management, 2(2), 99-110. 